\title{
Comparing Traditional Life Insurance Products in the Indian Market: A Consumer Perspective
}

\author{
Dr.L. Vijay and S. Tamilselvan
}

\begin{abstract}
Life insurance policies are valuable assets to mitigate the financial risk of untimely death. As such, every individual facing such a financial risk who can afford to pay for such a protection must seriously consider purchasing some life insurance. In the current Indian market, this choice is difficult on three counts:
\end{abstract}

- Inherent complexity due to uncertainty and long time horizons.

- The need to compare a plethora of different types of products from competing insurance companies.

- Most insurance policies bundle pure insurance with savings to offer composite products.

- There are two broad types of life insurance policies available in the Indian market:

i. Traditional' products consisting of Term Insurance, Endowment and Whole Life Policies

ii. 'Modern' products, which are unit-linked life insurance policies where the investment risks is borne by the policyholder.

- This paper is an attempt at a comparative evaluation of the Traditional Insurance Policies available in the Indian Market from a consumers' perspective:

i. Which type of traditional insurance product should I buy?

ii. Which insurance company's product should I buy?

iii. Is it better to save through insurance policies or through the widely available tax-

advantaged Public Provident Fund (PPF)?

- We use an expected present value approach, data on mortality rates, currently prevailing premiums on insurance policies and interest rates- for the comparison within and across policy types.

- We conclude as follows:

i. Shopping around will save a lot of money for an insurance buyer

ii. Term insurance should be the primary choice for insurance protection

iii. PPF is likely to be a better savings option than buying endowment or whole life policies.

Keywords--- Policyholder, Traditional Insurance Policies, Indian market, Insurance Regulatory and Development

Dr.L. Vijay, Professor, Department of Management Science, S.A. Engineering College, Chennai.

S. Tamilselvan, Lecturer, Department of Management Science, Gojan School of Business and Technology, Chennai.
Authority, Endowment Policy

\section{INTRODUCTION}

$\mathrm{L}$ IFE insurance is an appropriate financial tool for managing and mitigating the financial risk associated with untimely death. However, Life Insurance decisions are often complex. The choice of a life insurance product for an Indian Consumer is now a problem of plenty, even when confined to only traditional life insurance products-term insurance and cash value policies (i.e., whole life and endowment insurance). For any given product, we can choose from amongst several competing insurance companies. Depending only on a policy illustration provided by an insurance company can be a big mistake.

While comparing life insurance decisions, the concern of many financial planners is the quantitative assessment of the cost of protection against untimely death and the return on the savings component of the premium paid. Such an analysis can give a rational basis for comparing different Insurance Policies. In this paper, we perform such a comparison of traditional life insurance products. We propose to consider the unit-linked life insurance products in a follow-up paper.

\section{Choosing A POLICY}

It is difficult to apply any rule-of-thumb, because the amount of life insurance one individual needs depends on factors such as his/her wealth, sources of income, number of dependents, debts, and lifestyle and risk aversion.

In this paper, we do not venture into such questions. We restrict ourselves to a comparison of Insurance Policies for a given amount of death protection, term of protection, and/ or savings accumulation.

\section{VAluation of CASH Flows In Life Insurance}

A series of cash flows at different points in time can be valued for their Expected Present Value (EPV). The payments may include:

- Benefits receivable under the policy

- Premiums paid under the policy

The EPV depends upon the amount, timing, and the probability of uncertain events (mortality). For discount rates, usually a deterministic approach wherein the future interest rates are assumed to change in a pre-determined way is used. For mortality assumptions, we may use a life table function such as the one published by the Life Insurance Corporation of India (LIC), described below. 


\subsection{Mortality Table}

An insurance company should know with reasonable accuracy the chance of death at each age. A mortality table gives an estimate of how many, out of the members of a group starting at a certain age, are expected to be alive at each succeeding age. It is used to compute the probability of dying in or surviving through any period. The mortality table should be appropriate to the group of lives being insured.

The Insurance Regulatory and Development Authority (IRDA) requires that the mortality rates used shall be by reference to a published table, unless the insurer has constructed a separate table based on his own experience. In this study, we are using LIC's 1994-96 (ultimate) mortality table.

\subsection{Discount Rates}

Traditionally, a constant discount rate was used for all the years in the term. This was either the risk-free rate or the discount rate for a AAA-rated corporate bond, corresponding to the term of the policy. This practice is appropriate only if the term structure of interest rates can be assumed to be flat. This is typically not the case. Therefore, the current recommended practice is to discount each cash flow by the current zero-coupon yield on a treasury security or corporate debt of the same maturity.

\section{TERM INSURANCE}

A term insurance policy is a pure insurance product with no savings element. Term insurance provides financial protection against death within a specified period of time, paying a benefit only if you die during the term. Term policies will charge a lower premium than other types of insurance. This may be suitable for young people or for families on a limited budget that need large amount of life insurance protection. For them, the affordability of the premium is likely to be an important consideration. An easy way to compare the term policies in the market is to find out the policy charging the cheapest premium for a given amount of protection and term. Since term insurance is almost a commodity-type product, the cheapest is often the best.

Table 1: Comparison of Term Insurance Premiums (Rs./Year)

\begin{tabular}{|c|c|c|c|c|c|c|c|c|}
\hline \multirow[b]{2}{*}{ S. No } & \multirow[b]{2}{*}{ Company } & \multirow[b]{2}{*}{ Policy } & \multicolumn{6}{|c|}{ Term (years) } \\
\hline & & & 5 & 10 & 15 & 20 & 25 & 30 \\
\hline 1 & AMP Sanmar & Raksha Shree & 2230 & 2230 & 2290 & 2600 & 3070 & 3640 \\
\hline 2 & AVIVA & Life Shield & 2650 & 2660 & 2890 & 3120 & 3530 & 4060 \\
\hline 3 & Bajaj Allianz & Risk Care & 3260 & 3560 & 4050 & 4830 & 6050 & 7750 \\
\hline 4 & Birla Sunlife & Term Plan & 2950 & 2950 & 2950 & 3010 & 3160 &.-- \\
\hline 5 & HDFC & Term Assurance & 2770 & 2820 & 2870 & 2920 & 3050 & 3430 \\
\hline 6 & ICICI & Prudential LG & 3032 & 3032 & 3032 & 3032 & 3334 & 3905 \\
\hline 7 & Kotak Mahindra & Term Assurance & $\ldots$ & 3400 & 3400 & 3700 & 4100 & 4500 \\
\hline 8 & LIC & Amol Jeevan & 2564 & 2564 & 2812 & 23227 & 3821 & --- \\
\hline 9 & Max NewYork & Level Term & 2160 & 2280 & 2430 & 2700 & 3050 & --- \\
\hline 10 & Met Life & Suraksha & 2700 & 2600 & 2800 & 3100 & 3300 & $\ldots$ \\
\hline 11 & SBI & Life Shield & 2043 & 2043 & 2150 & 2454 & 2964 & $\ldots$ \\
\hline 12 & TATA AIG & Assure Life Line & $\cdots$ & 3510 & 3970 & 4550 & 5280 & $\ldots$ \\
\hline
\end{tabular}

For illustrative purposes, we consider a 30-year male. He is considering a level annual premium term policy for a sum assured of Rs.10, 00,000. Various terms under consideration are $5,10,15,20,25$ and 30 years. We consider the twelve term insurance policies available in the Indian market in this paper.

It can be seen from the table that:

- SBI Life Insurance provides the cheapest policy for the first five terms, i.e., up to 25 years. For the 30 -year term, HDFC Life Insurance is the cheapest.

- For some terms, the policies offered by some insurance companies can be more than twice as expensive as compared to the cheapest policy.

While it is entirely possible that offered by such expensive policies, they do not seem to offer value for money for the buyer.

Table 2

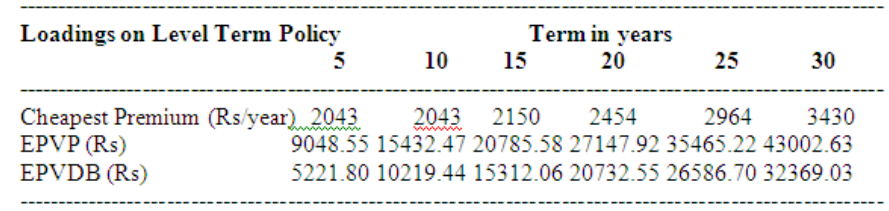

\section{ENDOWMENT POLICIES IN AN ENDOWMENT POLICY}

The benefit amount is payable either at the end of the term or upon the death of the insured person, whichever is earlier. Thus, an endowment policy is bundle $\mathrm{f}$ insurance cum savings, providing death protection as well as a maturity benefit. These policies are for a fixed tenure, usually up to 25 years, and the policy holder pays a fixed premium periodically during the premium paying period. Table 3 shows the premium structure of the endowment policies available in the Indian market1

Table 3: Premium Structure of Endowment Plans (Rs. /Year) Term in Years

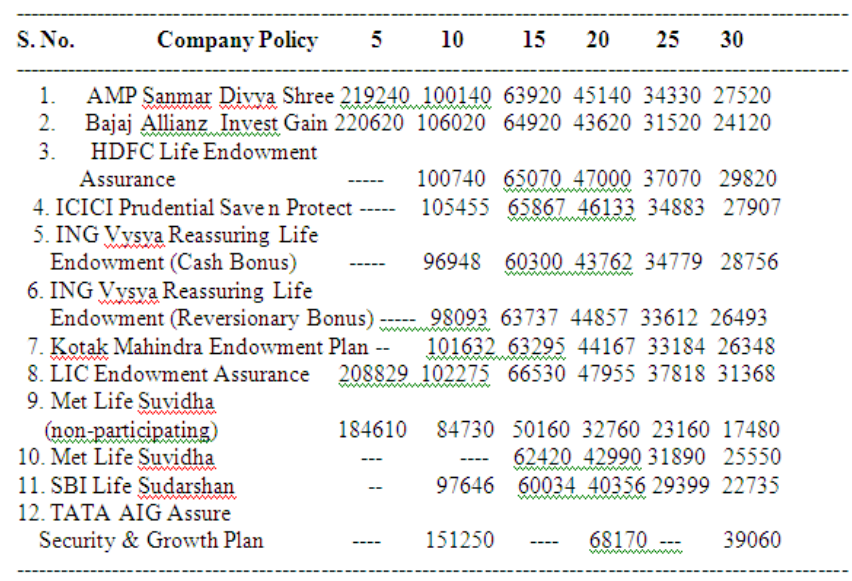

\subsection{Non-Participating Endowment Policy Vs Public Provident Fund (PPF)}

A non-participating endowment policy offers only one additional benefit over a term policy: maturity benefit equal to the sum assured (S.A). From its premium, if we subtract the annual premium for the cheapest term insurance policy for the same S.A, the extra premium earns us this extra maturity benefit. Therefore, we can compare this with the alternative of investing this extra premium in the best available pure savings vehicle11. We must realize that it would be a mistake to subtract the premium for the corresponding term insurance policy offered by the same insurer. This is a very likely 
mistake, as we normally compare an endowment premium to the term premium of the same insurer12. If their term insurance premium happens to be high, we may be talked up by the agent into buying their endowment policy instead. An endowment policy typically provides him a higher commission income. In Table 4, we have calculated the loading on the extra premium of Met Life's non-participating policy. We compare the expected incremental costs and benefits, with the cheapest term policy as the base: the Expected Present Value of the Extra Premium (EPVEP) versus the Expected Present Value of Extra Maturity Benefit (EPVMB).

Table 4: Loadings on Extra Premium of Met Life's NonParticipating Policy

\begin{tabular}{|c|c|c|c|c|c|c|c|}
\hline S.No. & Terms in Years & 5 & 10 & 15 & 20 & 25 & 30 \\
\hline 1. & \multicolumn{7}{|l|}{ Premium for Cheapest Term } \\
\hline & Policy for the same term & n 2043 & 2043 & 2150 & 2454 & 2964 & 3430 \\
\hline 2 & \multicolumn{7}{|c|}{ Non-Participating Endowment } \\
\hline & Policy Premium & 184610 & 84730 & 50160 & 32760 & 23160 & 17480 \\
\hline 3 & Extra Premium & 182567 & 82687 & 48010 & 303062 & 20196 & 14050 \\
\hline 4 & \multicolumn{6}{|l|}{ EPV of Extra Premium } & 1176147 \\
\hline 5 & \multicolumn{6}{|c|}{ EPV of the Extra Maturity } & 886430 \\
\hline
\end{tabular}

Table 5: AVPPF of Extra Premium of Participating Endowment Policies (Rs) Term in years

\begin{tabular}{|c|c|c|c|c|c|}
\hline S. No. C & Company Policy & 15 & 20 & 25 & 30 \\
\hline 1 & AMP Sanmar Divya Shree 3 & 3.57 & 3.47 & 3.44 & 3.50 \\
\hline 2 & Bajaj Allianz Invest Gain & 3.67 & 3.28 & 3.07 & 3.00 \\
\hline \multicolumn{6}{|c|}{ HDFC Life Endowment } \\
\hline & Assurance & 3.69 & 3.69 & 3.78 & 3.81 \\
\hline $\begin{array}{l}4 \text { ICICI } \\
5 \text { ING V }\end{array}$ & $\begin{array}{l}\text { I Prudential Saven Protect } \\
\text { Vysya Reassuring Life }\end{array}$ & 3.78 & 3.59 & 3.51 & 3.55 \\
\hline $6 \mathrm{ING} \mathrm{V}$ & $\begin{array}{l}\text { Endowment } \\
\text { Vysya Reassuring Life }\end{array}$ & 3.15 & 3.30 & 3.50 & 3.67 \\
\hline Endow & wment (Reversionary Bonus) & 3.54 & 3.44 & 3.35 & 3.36 \\
\hline 7 Kotak 1 & Mahindra Endowment Plan & 3.50 & 3.35 & 3.29 & 3.33 \\
\hline 8 LIC En & Endowment Assurance & 3.85 & 3.80 & 3.87 & 4.00 \\
\hline 9 Met Lif & Life Suvidha & 3.40 & 3.21 & 3.12 & 3.22 \\
\hline $10 \mathrm{SBI} L$ & Life Sudarshan & 3.12 & 2.87 & 2.76 & 2.77 \\
\hline \multicolumn{6}{|c|}{11 TATA AIG Assure Security \& } \\
\hline
\end{tabular}

Table 6: Minimum Required Compound Bonus Rate (in \%) Term in Years

\begin{tabular}{|c|c|c|c|c|}
\hline S.No. & Company Policy & 15 & 20 & 25 \\
\hline 1 & AMP Sanmar Divya Shree & 1796609 & 2085298 & 2438289 \\
\hline 2 & Bajaj Allianz Invest Gain & 1825694 & 2011043 & 2220626 \\
\hline $3 \mathrm{HD}$ & C Life Endowment Assurance & 1830057 & 2176163 & 2651287 \\
\hline \multicolumn{4}{|c|}{5 ING Vysya ReassuringLife } & 2481277 \\
\hline End & wment (Cash Bonus) & 1691319 & 2017980 & 2473192 \\
\hline \multicolumn{5}{|c|}{6 ING Vysya ReassuringLife } \\
\hline endo & vment (Reversionary Bonus) & 1791286 & 2071473 & 2382474 \\
\hline 7 Kota & Mahindra Endowment Plan & 1778430 & 2037765 & 2349202 \\
\hline $8 \mathrm{LIC}$ & ndowment Assurance & 1872522 & 2222816 & 2709434 \\
\hline 9 Met & ife Suvidha & 1752980 & 1980266 & 2248611 \\
\hline $10 \mathrm{SBI}$ & ife Sudarshan & 1683582 & 1851590 & 2054969 \\
\hline \multicolumn{3}{|c|}{11 TATA AIG Assure Security \& Growth Plan ...-. } & 3210360 & -.. \\
\hline
\end{tabular}

\section{WhOle-Life Policies IN A WhOle Life Policy}

The sum assured with bonus is paid out either on death or survival till a pre-determined age. Whole life policies expire at age 100. A few expire earlier. For example, ING Visa's Rewarding Life policy matures at 85 years. That means, on survival up to age 85 , the sum assured and accrued bonuses will be paid to the policy holder. Whole life insurance policies are valuable because they provide permanent protection and accumulate cash values for emergencies or bequeaths. Since it is unrealistic to expect the policyholders o keep paying level annual premiums beyond certain age, most insurance companies provide an option to the policyholders to pay their premiums over a shorter term called premium-paying term.

Table 8: Whole Life Insurance Premiums (Rs/Year) Premium Paying Term in Years 22

\begin{tabular}{lccc}
\hline \multicolumn{1}{c}{ Company Policy } & $\mathbf{1 5}$ & $\mathbf{2 0}$ & $\mathbf{2 5}$ \\
\hline 1 AMP Sanmar Nitya Shree & 36450 & 30000 & 26400 \\
2 Bajaj Allianz Life Time Care & 29760 & 24710 & 22140 \\
3 ING Vysya Rewarding Life & 44754 & 38358 & 35572 \\
4 LIC Jeevan Anand & 76292 & 54274 & 41206 \\
5 Met Life MET 100(non-participating) & 16900 & 14340 & 13030 \\
6 Met Life23MET 100 Gold & 32070 & 26700 & 23760 \\
\hline
\end{tabular}

We find that the loadings are very high. Since a whole life policy can be considered as an endowment till 100 years of age, this is in effect an endowment policy with a $70 \mathrm{yr}$ maturity period for a person who is 30 yrs of age. As such these loadings are in line with our earlier findings on endowment policies that loadings tend to increase with term of coverage.

Table 9

\begin{tabular}{|c|c|c|c|}
\hline Loadings on Whole Life Non-Participatin & ticipating & \multicolumn{2}{|c|}{$\begin{array}{l}\text { g Policy Met Life's Non-participating } \\
\text { Term in years }\end{array}$} \\
\hline & 15 & 20 & 25 \\
\hline $\begin{array}{l}1 \text { Non-Par Whole-life Premium } \\
2 \text { EPV of Non-Par Whole-life }\end{array}$ & 16900 & 14340 & 13030 \\
\hline $\begin{array}{l}\text { Premium (EPVP) } \\
3 \text { EPV of Non-Par Whole-life }\end{array}$ & 163384 & 158639 & 155908 \\
\hline Mortality Benefit (EPVMB) & 56917 & 56917 & 56917 \\
\hline $\begin{array}{l}\text { Loadings } 4 \text { Measure } 1: \\
\text { [EPVP-EPVMB] EPVMB } \\
\text { Measure } 2:\end{array}$ & 187.05 & 178.71 & 173.915 \\
\hline [EPVP-EPVMB] EPVP & 65.16 & 64.12 & 63.49 \\
\hline
\end{tabular}

The evaluation of participating whole life policies is a bit more involved. Since the premium paying term and the policy coverage term are different, we cannot follow the same method used in assessing participating endowment policies, using the cheapest term policy as the base. Instead, we use the non-participating whole life policy as the base. Suppose we invest the extra premium over the non-participating whole life policy (Met 100), in PPF .Table 10 gives our computed value of AVPPF.

Since we are comparing the accumulated values as at the end of the premium paying term, we need to value all bonus related cash flows also at the end of the premium paying term. The interpretation of the entries in table 11 is on similar lines to the entries in Table 7. Let us illustrate by discussing the meaning of the entry $2.38 \%$ for LIC's Jeevan Anand policy 
with a premium paying term of 20 yrs. LIC must pay a minimum of $2.38 \%$ as compound reversionary bonus, for this policy to be as good as PPF as an avenue for investing your extra premiums. We also notice that the minimum bonus rate required goes up as the premium paying term gets longer 25 . As is to be expected, larger the extra premium over Met 100, larger the minimum bonus rate required.

Table 10: AVPPF of Extra Premium of Participating Whole life Policies Premium Paying Term in years.

\begin{tabular}{lccc}
\hline Company Policy & $\mathbf{1 5}$ & $\mathbf{2 0}$ & $\mathbf{2 5}$ \\
\hline 1 Amp Sanmar Nitya Shree 568620 & 765022 & 1039339 \\
2 Bajaj Allianz Life & & & \\
Time Care & 374038 & 506595 & 708181 \\
3 ING Vysya Rewarding & & & \\
Life & 810146 & 1173328 & 1752340 \\
4 LIC Jeevan Anand 1727443 & 1950875 & 2190309 \\
5 Met life MET 100 Gold 441226 & 603811 & 834114 \\
\hline
\end{tabular}

Table 11: Minimum Required Compound Bonus Rate Premium Paying Term in years

\begin{tabular}{llccc}
\hline S. No & \multicolumn{1}{c}{ Company Policy } & $\mathbf{1 5}$ & $\mathbf{2 0}$ & $\mathbf{2 5}$ \\
\hline 1 & Amp Sanmar Nitya Shree & 1.00 & 1.26 & 1.56 \\
2 & Bajaj Allianz Life Time Care & 0.71 & 0.91 & 1.17 \\
3 & ING Vysya Rewarding Life & 1.55 & 2.00 & 2.55 \\
4 & LIC Jeevan Anand & 2.21 & 2.38 & 2.53 \\
5 & Met life MET 100 Gold & 0.81 & 1.04 & 1.33 \\
\hline
\end{tabular}

These have to be compared with the actual bonus rates announced by these companies in recent years. ING Vysya announced a 4\% compound reversionary bonus for 2003-04. Bajaj Allianz announced a compound reversionary bonus of 1.2\% for 2003-04. Life Insurance Corporation of India announced simple reversionary bonus rates for 2003-2004 of $4.9 \%$ to.3\%. AMP Sanmar has declared a simple reversionary bonus of $6 \%$ for 2004, inclusive of $2 \%$ as 'non-recurring'. Though these seem higher than the minimum bonus rates in Table 11, we must remember that our base is the nonparticipating whole-life policy Met 100. We saw in Table 9 that the loading on this policy itself was around $180 \%$. In addition, the quantum of bonus in future years is not guaranteed. Therefore, we can only say that, compared to Met 100 plus investments in PPF, participating whole-life policies seem equally attractive as an option for savings accumulation. But, as discussed earlier, PPF offers more flexibility and security.

\section{CONCLUSIONS}

It seems that it is much better for an individual to buy the cheapest term insurance for the required amount of death protection (sum assured) and term. Instead of buying the only non-participating endowment policy available in the Indian market, it seems better to invest the extra premium in a PPF account. The situation is not that clear cut between buying participating endowment policies versus buying the cheapest term policy and investing the difference in a PPF account. Inter-se comparisons between participating policies are difficult as they depend on the uncertain future investment performance and bonus policies of insurers. Instead, we have worked out the minimum compound reversionary bonus required under each policy for it to be Equivalent to investing the extra premium in a PPF account. Considering the bonus rates in the recent years, in our assessment, PPF seems to be a much safer and flexible alternative investment for the extra premium. In general, whole life policies are charging heavy loadings. A participating whole-life policy looks better only in comparison to buying a non-participating whole life policy and investing the extra premium in a PPF account. 